\title{
NEUROCHEMICAL AND HISTOLOGICAL BRAIN ALTERATIONS AFTER TRAMADOL ADMINISTRATION TO ROTENONE- INDUCED PARKINSON'S DISEASE IN RATS
}

\author{
Shaimaa A. ElShebiney $^{\mathrm{a}^{*}}$, Dalia M. Abuelfadl ${ }^{\mathrm{b}}$, Omar M. E. Abdel-Salam ${ }^{\mathrm{a}}$ \\ ${ }^{a}$ Department of Toxicology and Narcotics, National Research Centre (NRC), Cairo, Egypt \\ ${ }^{b}$ Department of Pathology, National Research Centre (NRC), Cairo, Egypt \\ * Corresponding author; Shaimaa A. ElShebiney, National Research Centre, 33 El-Buhouth st., \\ Dokki, P.O. 13211, Cairo, Egypt. Tel.: +20 33371362; fax: +20 33370931. E- \\ mail:shaimaaelshebiney@gmail.com
}

\begin{abstract}
Objective: Tramadol is favorably used for relief of moderate and severe pain. Over $30 \%$ of Parkinson's disease (PD) patients experience persistent pain that has a negative impact on their quality of life. However, its physiological effect in such disorder has not been studied. The current study aimed at investigating the neurochemical and histopathological changes resulting from tramadol administration to experimental PDinduced by rotenone in rats. Methodology: Forty adult male Sprague-Dawley rats were allocated into 5 equal groups; Group 1(control) received saline p.o and DMSO, s.c., Group 2(Rotenone) received rotenone (1.5 $\mathrm{mg} / \mathrm{kg}$, s.c., every other day for 12 days), Group 3 (Tramadol) received tramadol $\mathrm{HCl}$ given p.o., daily at doses of $20 \mathrm{mg} / \mathrm{kg}$, Group 4 (Rot-Trama 10) PD-induced with rotenone and treated with tramadol $\mathrm{HCl}, 10 \mathrm{mg} / \mathrm{kg}$, p.o., daily, Group 5(Rot-Trama 20) PD-induced with rotenone and treated with tramadol $\mathrm{HCl}, 20 \mathrm{mg} / \mathrm{kg}$, p.o., daily. Results: PD-induced rats exhibited significantly reduced dopamine (DA) content (- 33.0\%), increased serotonin ( 5-HT) content $(+11.5 \%)$, but no change in 5-hydroxyindole acetic acid (5-HIAA) compared to vehicle-treated counterparts. Rotenone also inhibited both brain paraoxonase 1 (PON1) and acetylcholinesterase (AChE) activities and increased brain oxidative stress causing reduced glutathione depletion by $32 \%$ and increasing thiobarbituric acid reactive substances (TBARS), nitric oxide (NO) by $43 \%$ and $81 \%$, respectively. Rotenone caused the appearance of apoptotic neurons with cytoplasmic vacoulations. On the other hand, tramadol -treated control rats showed increased DA (74\%), 5-HT (23\%), 5-HIAA (50\%) contents and decreased serotonin turnover (18.0\%) without causing oxidative stress. In rotenone-intoxicated rats, tramadol (10 or $20 \mathrm{mg} / \mathrm{kg}$ ) increased brain dopamine and at 20 $\mathrm{mg} / \mathrm{kg}$ increased 5-HT and 5-HIAA. The drug increased PON-1 activity, restored AChE activity and alleviated the changes in lipid peroxidation and reduced glutathione, increased tumour necrosis factor-alpha (TNF- $\alpha)$ without changing the histopathological changes caused by rotenone. Conclusion: These results indicate that short-term use of tramadol in an experimentally-induced PD has dual effects that should be carefully weighed. Tramadol decreased oxidative stress and restored normal DA content and AChE
\end{abstract}


activity that can help in PD. However, the drug resulted in increased proinflammatory cytokine TNF- $\alpha$ and 5-HT level.

Key words: Oxidative stress; tumour necrosis factor-alpha; rotenone; tramadol; Parkinson's disease

\section{INTRODUCTION}

Over $30 \%$ of Parkinson's disease (PD) patients experience persistent pain that has a negative impact on the patient's quality of life (Gallagher et al., 2010). However, in spite of pain being a common symptom in $\mathrm{PD}$, it is under treated (Chaudhuri et al., 2010). This pain is not associated with disease duration or severity and is responsive to dopaminergic therapies, although there is some alleviation with opiate-based remedies (Wallace and Chaudhuri, 2014).

Tramadol was marketed in Germany since 1977 as a potent analgesic and then introduced in the U.S. market and the world in 1995. It acts through central activation of $\mu$-opioid receptors and inhibition of norepinephrine and serotonin (5-HT) reuptake (Raffa et al., 1992; Desmeules et al., 1996). Tramadol is metabolized to a potent opioid agonist; o-desmethyltramadol with high relative intrinsic efficacy and moderate affinity for the $\mu$-opioid receptor (Volpe et al., 2011) and more potency than the parent drug (Gillen et al., 2000). It is used worldwide to alleviate moderate and severe pain resulting from such conditions as disc prolapse, joint disease, or cancer pain (Grond and Sablotzki, 2004).

Tramadol was reported to cause sustained symptomatic and functional improvement of PD patients and ceasing craving for supplemental carbidopa/levodopa therapy (Stein and Read, 1997). However, few data exists regarding the effects of tramadol on the pathophysiological process of PD.

Since the drug is a widely used analgesic and in view of its ability to modulate brain neurotransmitters that have an important contribution to the symptomatology of $\mathrm{PD}$, the current study aimed at investigating the neurochemical and histopathological changes resulting from tramadol administration to experimental PD induced by rotenone in rats. Rotenone is a pesticide of natural plant origin that has been shown to cause signs and symptoms of PD in rodents including motor abnormalities, nigrostriatal injury and alphasynuclein-like deposits (Sherer et al., 2003).

\section{MATERIAL AND METHODS}

\section{ANIMALS}

Forty adult male Sprague-Dawley rats $(120-140 \mathrm{~g})$ were obtained from the NRC breeding colony (Cairo, Egypt). Rats were kept for one week to accommodate at average room temperature $\left(23 \pm 2^{\circ} \mathrm{C}\right)$ and humidity. Food and water were provided ad libitum. National regulations of animal welfare and instructions of Institutional Animal Ethical Committee (IAEC) were followed.

\section{Chemicals, Drugs and treatments}

Rotenone was purchased from SigmaAldrich (St Louis, MO, USA) (cat\#110M114V). Rotenone was dissolved in $100 \%$ dimethyl sulfoxide (DMSO). It was given in dose of $1.5 \mathrm{mg} / \mathrm{kg}$, s.c. every other day for 12 days (6 doses) (EIShebiney et al., 2014). Tramadol tablets were officially provided by the Ministry of Justice (Egypt) and dissolved in saline to give $10 \mathrm{mg} / \mathrm{ml}$ solution. Doses were 10 and $20 \mathrm{mg} / \mathrm{kg}$ as corresponding to therapeutic usually used doses (Tsai et al., 2000). 


\section{EXPERIMENTAL DESIGN}

Rats were allocated into 5 equal groups ( $\mathrm{n}=8$ per group). Group 1 (Control) all 8 rats were given saline $0.5 \mathrm{ml}$, p.o. and DMSO 0.1 ml, s.c.. Group 2 (Tramadol) received tramadol $\mathrm{HCl}(20 \mathrm{mg} / \mathrm{kg}$, p.o., daily for two weeks) and DMSO (0.1 ml, s.c., every other day) and used as a reference treatment group.

Group 3 (ROT) received only rotenone (1.5 mg/kg, s.c., every other day for 12 days). Group 4, (ROT-Trama 10) in concomitance with rotenone treatment $(1.5 \mathrm{mg} / \mathrm{kg}$, s.c., every other day for 12 days) 8 rats were treated with tramadol $\mathrm{HCl}$ at dose of 10 $\mathrm{mg} / \mathrm{kg}$, p.o. daily.

Group 5 (ROT-Trama 20) in concomitance with rotenone treatment (1.5 $\mathrm{mg} / \mathrm{kg}$, s.c., every other day for 12 days) 8 rats were treated with tramadol $\mathrm{HCl}$ at dose of $20 \mathrm{mg} / \mathrm{kg}$, p.o. daily. Twenty-four hours after the last treatment, rats were euthanized by decapitation and cerebrum was rapidly removed, divided into two hemispheres. One cerebral hemisphere was dissected and cerebral cortex was separated on ice cold plate and kept frozen at $-20^{0} \mathrm{C}$ for biochemical analysis. The other hemisphere was kept in formol saline for histopathological investigation.

\section{NEUROCHEMICAL STUDIES}

DETERMINATION OF SEROTONIN, 5HYDROXYINDOLE ACETIC ACID AND DOPAMINE CONTENT

The concentrations of serotonin (5hyroxytryptamine: 5-HT), 5-hydroxyindole acetic acid (5-HIAA) and dopamine (DA) were estimated in the cortex fluoremetrically. Cortical samples were extracted by acidified butanol and purified as previously described (Ciarlone, 1978). 5-HT and 5-HIAA were determined through reactivity with Ophthaldehyde and measured at excitation and emission wavelength 360-470 nm, while DA was determined by iodine reaction and measured at excitation and emission wavelength 320-375 nm (Ciarlone, 1978).

\section{ASSESSMENT OF OXIDATIVE STRESS PARAMETERS}

The content of reduced glutathione (GSH) was determined according to the method of Beutler et al. (1963) using Ellman's reagent and the color produced is read spectrophotometrically at $412 \mathrm{~nm}$. Lipid peroxides expressed as thiobarbituric acid reactive substances (TBARS) were colorimetrically assayed as described by Uchiyama and Mihara (1978). Nitric oxide (NO) was determined using Griess reagent, the absorbance was read at $540 \mathrm{~nm}$ (Moshage et al., 1997).

The spectrophotometrical method of Gan et al. (1991) was used for the determination of paraoxonase (PON1) activity. PON1 is an important antioxidant enzyme (Aviram et al., 1998). The enzyme catalyzes phenyl acetate cleavage into phenol that is measured at 270 nm.

\section{ACETYLCHOLINESTERASE (ACHE) ACTIVITY}

The activity of AChE was determined using the method of Ellman et al. (1961). The absorbance is recorded every 30 seconds at $412 \mathrm{~nm}$ for two minutes and difference of absorbance is calculated and estimated in terms of IU/L.

\section{TUMOR NECROSIS FACTOR (TNF)- $\alpha$}

The level of TNF- $\alpha$ was measured by ELISA commercial kit supplied by Thermofischer scientific co, USA according to the manufacture instructions.

HISTOPATHOLOGICAL INVESTIGATION 
Different samples of brain tissue were fixed in $10 \%$ formol saline for 24 hours. Samples were washed by tap water and then serially dehydrated with ascending grades of alcohol. Specimens were cleared in xylene and embedded in paraffin. Paraffin blocks were prepared for sectioning at $4 \mu \mathrm{m}$ by sledge microtome. The obtained tissue sections were collected on glass slides, deparaffinized, and stained by hematoxylin and eosin for histopathological examination under the electric light microscope (Banchroft et al.1996).

\section{STATISTICAL ANALYSIS}

All data are presented as mean \pm standard error of the means (SEM). Comparison between groups was carried out using the non-parametric one-way analysis of variance (ANOVA) followed by TukeyKramer multiple comparisons test. Difference was considered significant at $\mathrm{p}<$ 0.05. Graphpad Prism 5.00 for windows software (CA, USA) was used to carry out these statistical tests and plot graphs.

\section{RESULTS}

No mortalities were observed after the administration of tramadol to rotenonetreated animals in the current study.

\section{NEUROCHEMICAL STUDIES}

\section{SEROTONIN, 5-HYDROXYINDOLE ACETIC ACID AND DOPAMINE CONTENT}

In control animals, tramadol significantly increased DA level (74\%, $\mathrm{p}<0.05)$, 5-HT level $(23 \%, \mathrm{p}<0.05)$, and 5HIAA level $(50 \%, \mathrm{p}<0.05)$ when compared to the control animals. Serotonin turnover rate was decreased by $18 \%$ compared to the control animals (Fig.1).
Rotenone administration resulted in markedly reduced DA level $(33 \%, \mathrm{p}<0.05)$, while 5-HT level was increased $(11.5 \%$, $\mathrm{p}<0.05)$ compared to the control group. On the other hand, there were no changes in 5HIAA level or the turnover rate of serotonin in rotenone-treated rats compared to the control group (Fig.1).

In rotenone-treated animals, administration of tramadol at doses of 10 or $20 \mathrm{mg} / \mathrm{kg}$ restored the normal DA level but did not alter the rotenone-induced 5-HT elevation. In contrast, the metabolite 5-HIAA concentration was increased in rotenonetreated animals administered tramadol (20 $\mathrm{mg} / \mathrm{kg}$ ) compared with the rotenone-only treated group (15.5\%). There was no change of serotonin turnover rate (Fig.1).
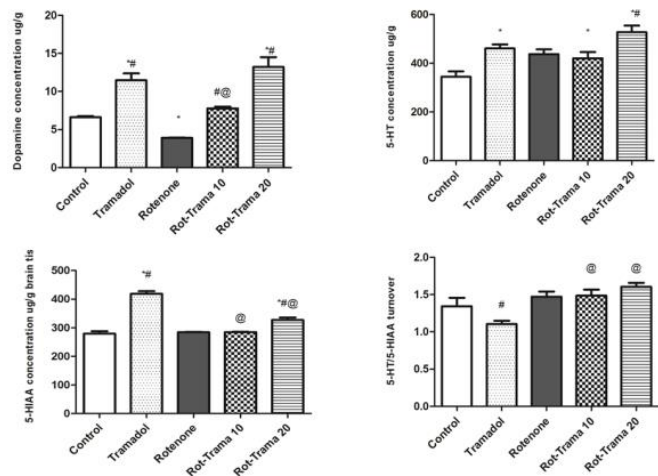

Figure (1): Effect of tramadol administration on neurotransmitters in cerebral cortex of normal or rotenone-induced PD rats. Data are mean $(n=8)$ \pm S.E.M. ${ }^{*} P<0.05$ vs. normal control, ${ }^{+} P<0.05$ vs. rotenone group. Statistical analysis was carried out by one-way ANOVA followed by TukeyKramer multiple comparison test.

\section{OXIDATIVE STRESS MARKERS}

Tramadol administration to non PD animals did not change the levels of any oxidative biomarker as compared to control animals.

Rotenone induced oxidative stress state 0in the cortex; GSH content was decreased (32\%, p<0.05), while TBARS and NO contents were elevated $(43 \%$ and $81 \%$, 
$\mathrm{p}<0.05)$ as compared to control rats. The administration of tramadol (10 and 20 $\mathrm{mg} / \mathrm{kg}$ ) alleviated the rotenone-induced alteration in GSH $(50 \%$ and $41 \%, \mathrm{p}<0.05)$ and reduced TBARS $(-20 \%$ and $-24 \%$, $\mathrm{p}<0.05)$. However, there was no effect for tramadol on the level of NO in rotenonetreated rats (Table 1). In normal rats, tramadol had no effect on PON1 activity (Fig.3).The PON1 activity was reduced by rotenone $(51 \%, \mathrm{p}<0.05)$. However, tramadol given at 10 or $20 \mathrm{mg} / \mathrm{kg}$ to rotenone-treated rats resulted in restoration of PON1 activity ( $120 \%$ and $100 \%$ of control value, $\mathrm{p}<0.05$ ) (Table 1).

Table (1): Oxidative state of cerebral cortex of rats after tramadol, rotenone or rotenone-tramadol administration

\begin{tabular}{|c|c|c|c|c|}
\hline & $\begin{array}{l}\text { GSH } \\
\mu \mathrm{mol} / \mathrm{g} \text { tissue }\end{array}$ & $\begin{array}{l}\text { TBARS } \\
\text { nmol/g tissue }\end{array}$ & $\begin{array}{l}\mathrm{N} 0 \\
\text { umolig tissue }\end{array}$ & $\begin{array}{l}\mathrm{PONl} \\
\mathrm{IU} / \mathrm{g} \text { wet tissue }\end{array}$ \\
\hline Control & $1.15 \pm 0.03$ & $37.07 \pm 1.48$ & $12.20 \pm 0.35$ & $3.9 \pm 0.42$ \\
\hline Tramadol & $1.12 \pm 0.03$ & $37.20 \pm 1.54$ & $11.76 \pm 0.56$ & $1.90 \pm 0.17^{t}$ \\
\hline ROT & $0.78 \pm 0.05^{+}$ & $53.02 \pm 2.96^{\dagger}$ & $22.10 \pm 1.62^{*}$ & $3.37 \pm 0.54$ \\
\hline R0T-Trama 10 & $1.17 \pm 0.02^{-}$ & $40.22 \pm 1.53^{+}$ & $22.79 \pm 0.85^{*}$ & $6.87 \pm 0.47^{t}$ \\
\hline ROT-Trama 20 & $1.09 \pm 0.02^{+}$ & $42.18 \pm 2.07^{+}$ & $22.54 \pm 0.96^{*}$ & $3.82 \pm 0.31$ \\
\hline
\end{tabular}

Data are mean $(\mathrm{n}=8) \pm$ S.E.M. ${ }^{*} P<0.05$ vs. control, ${ }^{+}$ $P<0.05$ vs. ROT group. Statistical analysis was carried out by one-way ANOVA followed by Tukey-Kramer multiple comparison test.

\section{ACETYLCHOLINESTERASE $(\mathrm{ACHE})$ \\ ACTIVITY}

Rotenone suppressed AChE activity in comparison to control animals $(17.79 \pm 0.27$ vs. $20.43 \pm 1.63 \mathrm{U} / \mathrm{L}, \mathrm{p}<0.05)$. The activity of AChE was increased after tramadol administration to non PD animals $(25.91 \pm 0.67$ vs. $20.43 \pm 1.63 \mathrm{U} / \mathrm{L}, \mathrm{p}<0.05)$ and also after its administration to rotenone- treated rats $(29.64 \pm 1.42$ and $18.79 \pm 0.89 v s$. 17.79 \pm 0.27 U/L, p<0.05) (Fig.2).

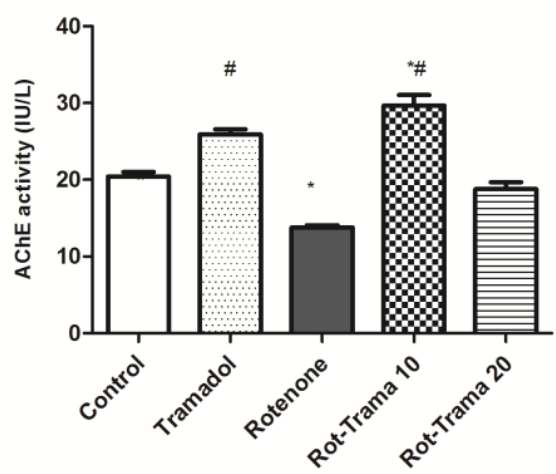

Figure (2): Effect of tramadol administration on acetylcholinesterase activity in normal and PD-induced rats. Tramadol induced its activity in normal and diseased animals. Data are mean $(\mathrm{n}=8) \pm$ S.E.M. ${ }^{*} P<0.05$ vs. normal control, ${ }^{+} P<0.05$ vs. rotenone group. Statistical analysis was carried out by one-way ANOVA followed by TukeyKramer multiple comparison test.

\section{TUMOR NECROSIS FACTOR (TNF)- $\alpha$}

Rotenone administration had no significant effect on TNF- $\alpha$ compared with the control group. Similarly, tramadol administration failed to affect TNF- $\alpha$ level in normal rats. In contrast, there was a marked increase in TNF- $\alpha$ level in rats administered both rotenone and tramadol 10 and $20 \mathrm{mg} / \mathrm{kg}$ (84\% and $71 \%, \mathrm{p}<0.05)$ compared to the control group (Fig. 3). 


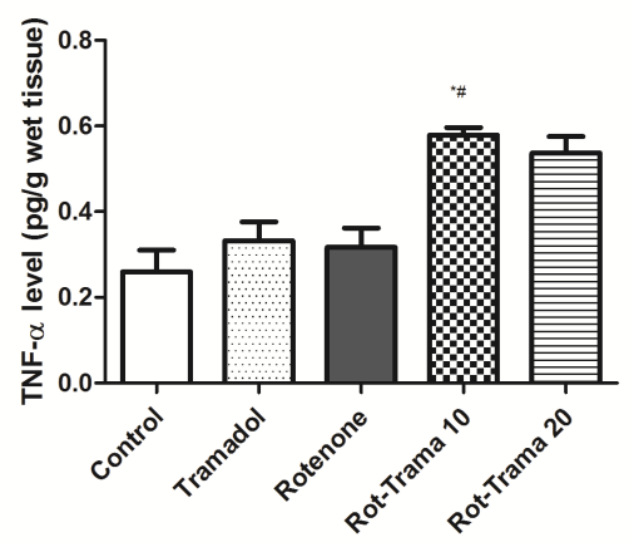

Figure (3): Effect of tramadol administration on TNF-acontent in cerebral cortex of normal and PD-induced rats. Tramadol $(10 \mathrm{mg} / \mathrm{kg})$ elevated its level in diseased animals. Data are mean $(\mathrm{n}=8) \pm$ S.E.M. ${ }^{*} P<0.05$ vs. normal control, ${ }^{+} P<0.05$ vs. rotenone group. Statistical analysis was carried out by one-way ANOVA followed by Tukey-Kramer multiple comparison test.
Examination of $\mathrm{H} \& \mathrm{E}$ stained sections of control group showed that the cerebral cortex have well organized nerve cells. The granular cells appeared rounded in shape and showed large rounded vesicular nuclei with prominent nucleoli (Fig.4a). Only edema was noticed in brains of tramadol-administered rats (Fig.4b). Rotenone injection caused focally apoptotic neurons and appearance of pyknotic nuclei surrounded by marked cytoplasmic vacuolations (Fig.4c). However, tramadol 10 or $20 \mathrm{mg} / \mathrm{kg}$ given to rotenonetreated rats did not exacerbate the pathological changes observed in brain as compared to rotenone-only administered rats. Neuroinflammation and pyknotic nuclei with cytoplasmic vacuolations was observed in the group treated with tramadol $10 \mathrm{mg} / \mathrm{kg}$. Rats treated with tramadol $20 \mathrm{mg} / \mathrm{kg}$ showed widely enlarged neurons and unarranged neuronal cells with edema (Fig.4d \& e).

\section{HISTOPATHOLOGICAL RESULTS}

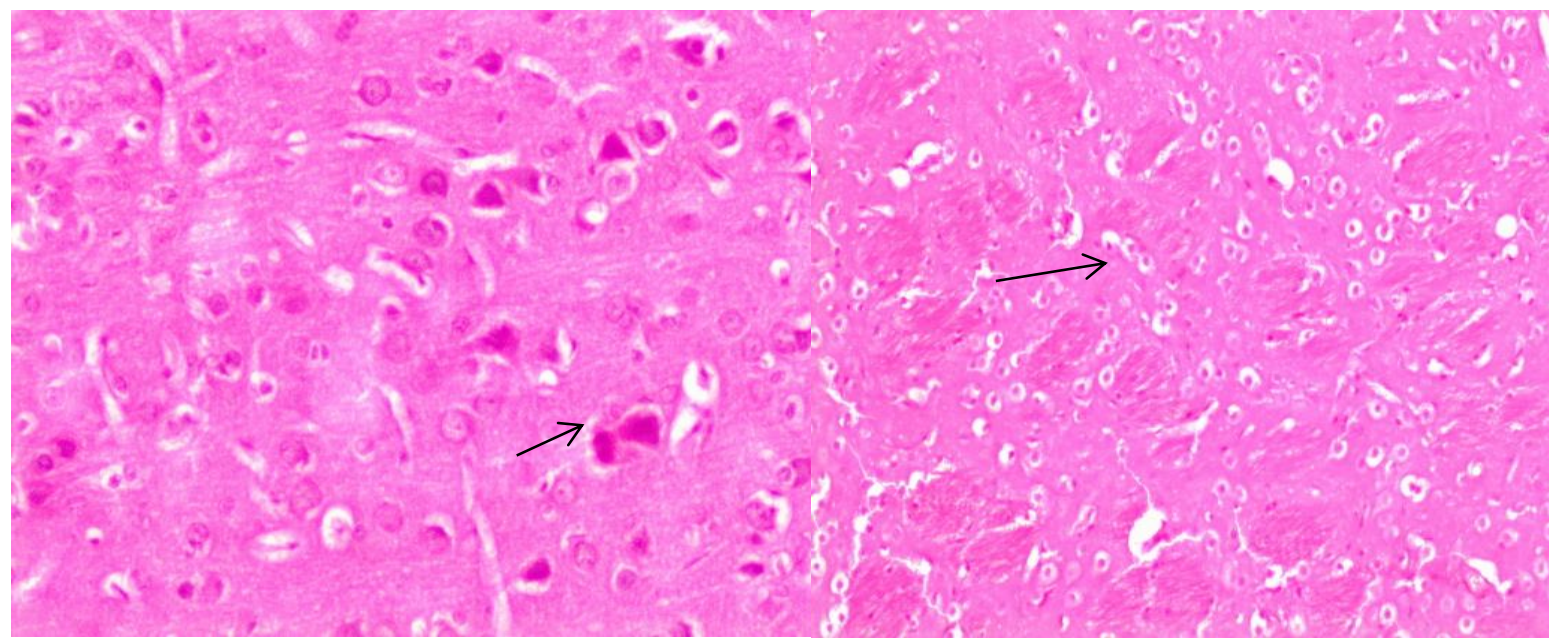

Fig. (4a): Tissue of cerebral cortex of control rats showing well organized nerve cells. The granular cells appeared rounded in shape and showed large rounded vesicular nuclei with prominent nucleoli (x100).
Fig. (4b): Cerebral cortex of tramadol group showing normal looking tissue with focal cytoplasmic vacuolation. Only edema was noticed (x100). 


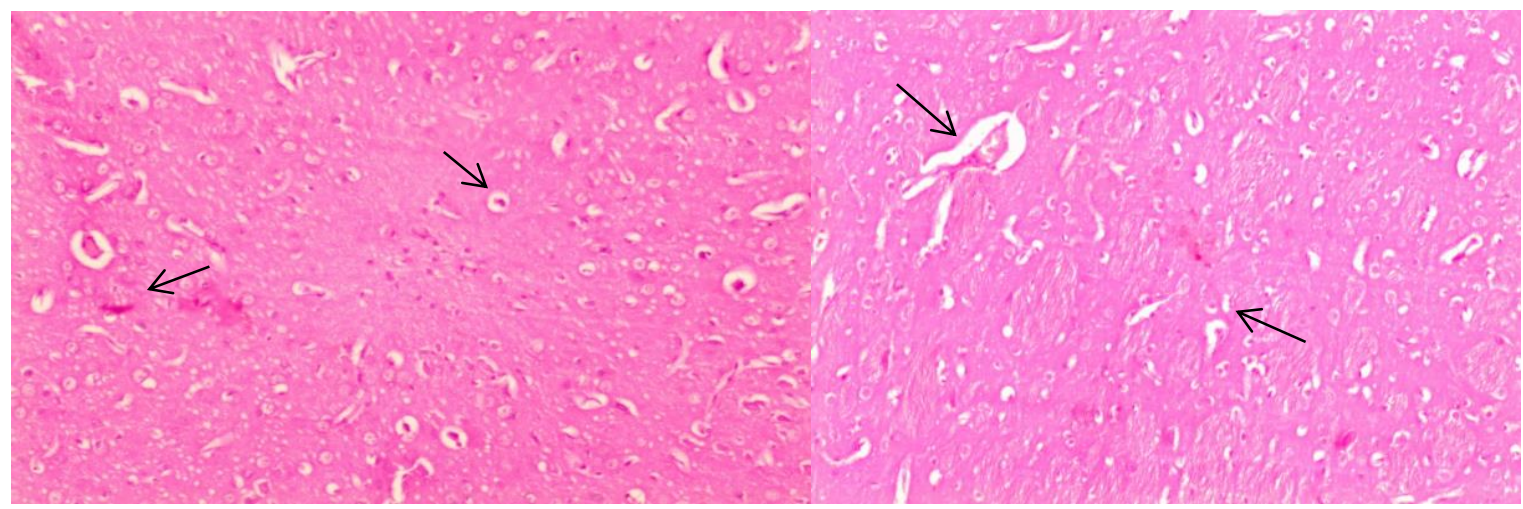

Fig. (4c): Rotenone administration showed cytoplasmic vacuolations and focally apoptotic neurons ( $x 100)$

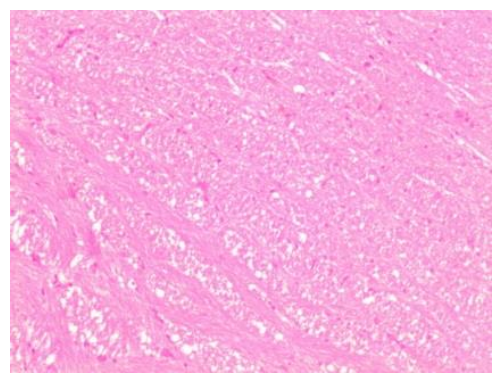

Fig. (4e): Tramadol $20 \mathrm{mg} / \mathrm{kg}$ administration to rotenone-treated animals showing widely enlarged neurons and edema. Better pathological picture than rats treated with rotenone only (x100).

\section{DISCUSSION}

The current study explored the effects of tramadol use in an experimental model of PD. In rodents, the insecticide rotenone was used to induce the pathological features of PD (Betarbet et al., 2002; Nehru et al., 2008, ElShebiney et al., 2014) by destroying the dopaminergic neurons in substantia nigra causing depletion of associated neurotransmitters (Saravanan et al., 2006, Zaitone et al., 2012). Rotenone also causes the
Fig. (4d): Tramadol $10 \mathrm{mg} / \mathrm{kg}$ administration to rotenone-treated animals showing moderate neuronal degeneration and cytoplasmic vacuolations (x100)

appearance of $\alpha$-synuclein like deposites in addition to manifesting the underlying pathophysiological mechanisms including oxidative stress and neuroinflammation (Schapira and Jenner, 2011; Manjunath and Muralidhara, 2013). Oxidative stress and neuroinflammation are thought to be major mechanisms in both genetic and idiopathic cases of PD (Dawson and Dawson, 2003).The findings of the present study demonstrated DA depletion and 5-HT elevation after rotenone, which was previously reported by our lab (ElShebiney et al., 2014). Besides, there was depletion of GSH which is in agreement with that reported by several investigators following rotenone administration in rodents (Betarbet et al., 2002; Saravanan et al., 2006; Sherer et al., 2007; Al-Quraishy et al., 2012) and oxidative stress byproducts were increased such as TBARS and NO in accordance with other reports (Sherer et al., 2007; Zaitone et al., 2012 ; EIShebiney et al., 2014). 
Since tramadol is recommended in chronic pain patient groups, and among them PD patients, we studied the possible modulation of the neurochemical and histopathological alterations in experimental PD by the drug. Our findings indicated that normally tramadol administration increased cortical DA content in normal and PD animals. Progressive depletion of DA in midbrain basal ganglia is the hallmark of the disease owing to the continuing death of the DA containing neurons of the substantia nigra pars compacta and the striatum (Smith and Villalba, 2008). When DA reaches around 50\% depletion in these areas, patients start to experience motor changes characteristic of the disease i.e., bradykinesia and muscular rigidity (Bernheimer et al., 1973). The increase in DA level in rotenone-treated rats by tramadol (10 or $20 \mathrm{mg} / \mathrm{kg}$ ) could be due to enhanced DA release which has been reported previously (Gan et al., 2007; Raffa, 2008; Somogyi et al., 2007; Hassanian-Moghaddam et al., 2013). An imbalance between DA and ACh is also thought to contribute to the development of symptoms in PD and anticholinergic drugs were used in the past before the advent of DA replacement therapy for symptom alleviation and still in use for mild cases (Schwab et al., 1939; Corbin, 1949; Lang, 1984). The main cholinergic neurotransmitter ( $\mathrm{ACh}$ ) modulates motor control in basal ganglia (Dani and Bertrand, 2007) and cognitive functions in cortical areas (Hasselmo and Sarter, 2011), in addition it regulates neuronal activity (Dani and Bertrand, 2007) and stress response (Mansvelder et al., 2009). The cholinergic transmitted signals diminish through cleavage of $\mathrm{ACh}$ by $\mathrm{AChE}$, which activity is used as indicator for cholinergic neurotransmission dysfunction. The inactivation of AChE after rotenone administration is mainly due to direct reactive oxygen species interaction (Klegeris et al., 1995). Inhibited AChE activity and increased ACh content in different brain regions of rats after rotenone injection was reported in line with current observation (Swathi et al. 2013). Tramadol (10 and $20 \mathrm{mg} / \mathrm{kg}$ ) was able to attenuate the rotenoneinduced inhibition and elevate $\mathrm{AChE}$ activity in the present study hence restores ACh normal activity. The produced changes after tramadol administration in DA and ACh contents add a therapeutic value to use of tramadol in such disorder.

Tramadol increased cortical levels of 5-HT and its main metabolite 5-HIAA as well so decreased serotonergic turnover rate in non PD animals. In PD animals, tramadol at both doses increased 5-HT but did not affect 5-HIAA or 5-HT turnover rate. These observations are important in view of the fact that the neurotransmitter 5-HT plays an important role in the development of symptoms in PD patients (Scholtissen et al., 2006) since a decrease of striatal 5-HT and its metabolite 5-HIAA was also described in postmortem PD brains (Kish et al., 2008). 5-HT has an inhibitory effect on striatal DA release (De Deuerwaerdere et al., 2004). The balance between 5-HT and other neurotransmitters was reported to be responsible for the clinical symptoms in PD patients receiving tramadol (Mellor et al., 2009). The drug was reported to reduce the levels of 5-HT 
and its metabolite 5-HIAA (Frink et al. 1996). Unchanged 5-HIAA level in PD subjects reflects the enhanced oxidative state where the oxidative deamination may be lowered (Miguez et al., 1999). On the other hand, serotonin syndrome was reported following tramadol use (Takeshita and Litzinger, 2009; Tashakori and Afshari, 2010). However, most reports are for tramadol by itself without being in interaction with a brain disease such as PD. Our observation suggests that short term tramadol has no deleterious effect on the serotonergic system which is inhibited in PD. We thereby recommend having tramadol treatment in PD on individualized basis as there are no criteria for the occurrence of serotonergic syndrome or 5-HT associated seizures.

Oxidative stress undoubtly contributes to the neurodegeneration seen in PD and evidence for oxidatively modified cellular molecules have been found in the post-mortem brain of sporadic PD patients (Jenner, 2003). In genetic forms of the disease, accumulating evidence also indicates increased oxidative stress resulting from mitochondrial dysfunction and activated microglia in these subjects (Obeso et al., 2010; Taylor et al., 2013; Tufi et al., 2014). Oxidative stress occurs when oxygen free radicals are produced in excessive amounts that cannot be efficiently removed by the cell's antioxidant mechanisms. The consequences are membrane lipid peroxidation and altered membrane fluidity, damage to the cell DNA and enzymes (Chong et al., 2005). In the present study, the short term administration of tramadol to normal rats had no significant effect on the normal oxidative state. In rotenone-treated rats, however, the drug increased GSH and decreased lipid peroxidation (TBARS) and enhanced activity of PON1. Thereby, tramadol use in the present study (10 or $20 \mathrm{mg} / \mathrm{kg}$ ) was found to have ameliorative effects on the oxidative insult that occurred during progression to $\mathrm{PD}$, which indicates its supportive role in such condition. It is to be noted that the present findings are related only to shortterm administration of tramadol. This finding is also in accordance with other studies showing an acute protective effect for tramadol $(20 \mathrm{mg} / \mathrm{kg})$ against ischemia-induced stress together with improved antioxidant status (Bilir et al. 2007; Takhtfooladi et al., 2014). Similarly, Sen et al. (2013) reported increased antioxidant activity and a decrease in the oxidative stress marker TBARS after tramadol administration at $30 \mathrm{mg} / \mathrm{kg}$ for formalin-induced inflammation model in rats. In addition tramadol reduced TBARS level in rat model of ischemia (Nagakannan et al., 2012). Other researchers, however, recorded a significant increased TBARS level and decreased GSH and antioxidant enzymes (superoxide dismutase and catalase) after longer tramadol treatment of rats (40 mg/kg for 20 days) (Awadalla \& Salah-Eldin, 2016). In another study, repeated tramadol administration (50 $\mathrm{mg} / \mathrm{kg}$ ) to mice resulted in increased $\mathrm{NO}$ and TBARS (Abdel-Zaher et al., 2011). Recent studies addressed the role of $\mathrm{NO}$ in learning, memory and cognitive functions in addition to many other regulatory functions (Steinert et al., 2010). However, high NO levels indicate 
free radical damage of cells and implicate protein nitrosative damage therefore it was associated to pathophysiology of some neurodegenerative diseases such as PD and multiple sclerosis (Lima-Cabello et al., 2016). The current study showed its elevation upon induction of disease but was not altered by tramadol treatment, an effect that may be attributed to short term use.

The enzyme PON-1 is present on high density lipoprotein (HDL) and catalyzes the hydrolysis of numerous toxins and aromatic compounds resulting in the ultimate anti-inflammatory and anti-oxidant functions of HDL (Rosenblat et al., 2006). The altered redox state of brain in neurodegenerative diseases was also associated with impaired PON-1 enzyme activity (Castellazzi et al., 2016). Restoration of this enzyme activity by tramadol in the current study is an added evidence of its antioxidant effect in this disease.

Neuroinflammation is a process whereby microglia get activated and release several growth factors and cytokines in response to stressors as a primary immune mechanism; the accumulation of these neurokines set an inflammatory condition in the brain leading to cellular damage (Han et al., 2011). There is evidence for increased proinflammatory cytokines such as IL- $1 \beta$ and TNF- $\alpha$ in the brain of patients with PD. Sacerdote et al.(1997) reported antiinflammatory effect and inhibited proinflammatory cytokine IL-1 production after acute administration and a reverse effect after chronic administration to rats through a serotonergic mechanism. Similarly, Liu et al. (2008) show that IL-6 levels were lowest when $20 \mathrm{mg} / \mathrm{kg}$ of tramadol acutely administered in the incision pain model in rats. The inflammatory biomarker, TNF- $\alpha$ is mainly secreted by glial cells. In the present study, we found no significant effect for tramadol on the inflammatory biomarker TNF- $\alpha$ in brain of control rats. However, TNF- $\alpha$ was elevated after tramadol administration to rotenone-treated animals. The most notable unexpected finding that tramadol elicited neuroinflammation in PD brain, which may be attributed to the serotonergic dual upsurge. However, the observed elevated TNF- $\alpha$ was not enough to cause exacerbation of the histopathological changes strengthening the need for further long-term studies to explore the tramadol-associated modulatory effects. In the current study, tramadol had no deleterious effects on normal or PD brain tissue. The cerebral cortex showed degenerative changes after rotenone administration which can be a result of oxidative status of brain and was not ameliorated by tramadol administration. Ghoneim et al. (2014) and Awadalla and Salah- eldin, (2016) reported apoptotic changes in cerebral cortex after long term tramadol administration at high doses.

\section{CONCLUSIONS}

It can be concluded that in an experimentally induced model of PD, the use of short-term tramadol decreased oxidative stress and restored normal DA content and AChE activity that can help in PD. However, the drug resulted in increased proinflammatory cytokine TNF- $\alpha$ and 5-HT level in PD-induced 
animals. We found no exacerbation of the rotenone-induced histopathological changes by short-term tramadol administration in moderate therapeutic doses. Thus, the use of tramadol for such disease can be recommended. However, future long term studies should be carefully weighed and thoroughly investigated.

\section{RECOMMENDATION}

Tramadol is suitable for pain associated with chronic neurodegenerative disease such as PD but further studies are required for long term use specially on serotonergic system.

\section{ACKNOWLEDGMENT}

None

\section{CONFLICTS OF INTEREST}

The authors declare that there are no conflicts of interest

\section{REFERENCES}

\section{Abdel-Zaher, A.O.; Abdel-Rahman, M.S.; Elwasei, F.M. (2011). Protective effect of Nigella Sativa oil against tramadol-induced tolerance and dependence in mice: role of nitric oxide and oxidative stress. Neurotoxicology, 32 (6): 725-733.}

Al-Quraishy, S.; Dkhil, M.A.; Moneim, A.E.A. (2012). Protective effects of Portulaca oleracea against rotenone mediated depletion of glutathione in the striatum of rats as an animal model of Parkinson's disease. Pesticides Biochemistry and Physiology, 103:108-114.
Aviram,M.; Rosenblat, M.; Bisgaier, C.L.; Newton, R.S.; Primo-Parmo, S.L. and La Du, B.N. (1998). Paraoxonase inhibits high-density lipoprotein oxidation and preserves its functions. A possible peroxidative role for paraoxonase. Journal of Clinical Investigation, 101: 15811590.

Awadalla, E.A. and Salah-Eldin, A-E. (2016). Molecular and histological changes in cerebral cortex and lung tissues under the effect of tramadol treatment, Biomedicine \& Pharmacotherapy 82: 269-280.

Banchroft, J.D.; Stevens, A. and Turner, D.R. (1996). Theory and practice of histological techniques. $4^{\text {th }}$ Ed, Churchill Livingstone, Philadelphia, PA, USA; 25-90.

Bernheimer, H.; Birkmayer, W. and Hornykiewicz, O. (1973). Brain dopamine, the syndrome of Parkinson's and Huntington: Clinical, morphological, neurochemical correlations. Journal of Neurological Sciences, 20: 415-455.

Betarbet, R.; Sherer, T.B. and Greenamyre, J.T. (2002). Animal models of Parkinson's disease. Bioessays, 24(4):308-318.

Beutler, E.; Duron, O. and Kelley, B.M. (1963). Improved method for the determination of blood glutathione. Journal Laboratory and Clinical Medicine, 61: 882-888.

Bilir, A.; Erkasap, N. and Koken, T. (2007). Effects of tramadol on myocardial ischemia-reperfusion 
injury. Scandanivian Cardiovascular Journal, 41:242-247.

Castellazzi, M.; Trentini, A.; Romani, A.; Valacchi, G.; Bellini, T.; Bonaccorsi, G.; et al. (2016). Decreased arylesterase activity of paraoxonase-1 (PON-1) might be a common denominator of neuroinflammatory and neurodegenerative diseases. The International Journal Of Biochemistry \& Cell Biology, 81, 356-363.

Chaudhuri, K.R.; Prieto-Jurcynska, C.; Naidu, Y.; Mitra, T.; FradesPayo, B.; Tluk, S.; et al. (2010). The non declaration of non motor symptoms of PD disease to health care professionals: an international study using the non motor symptoms questionnaire.

Movement

Disordorders, 25:704-712.

Chong, Z.Z.; Li, F. and Maiese, K. (2005). Oxidative stress in the brain: novel cellular targets that govern survival during neurodegenerative disease. Progress in Neurobiology, 75(3): 207-246.

Ciarlone, A.E. (1978). Further modification of a fluorometric method for analyzing brain amines. Microchemical Journal, 23(1): 9-12.

Corbin, K.B. (1949). Trihexyphenidyl (Artane): the evaluation of a new agent in the treatment of parkinsonism. JAMA, 141: 377-382.

Dani, J.A. and Bertrand, D. (2007). Nicotinic acetylcholine receptors and nicotinic cholinergic mechanisms of the central nervous system. Annual
Review of Pharmacology and Toxicology, 47:699-729. PubMed PMID: 17009926.

Dawson, T.M. and Dawson, V.L. (2003). Molecular pathways of neurodegeneration in Parkinson's disease. Science, 302:819-822.

De Deuerwaerdere, P.; Navailles, S.; Berg, K.A.; Clarke, W.P. and Spampinato, U. (2004). Constitutive activity of the serotonin $2 \mathrm{C}$ receptor inhibits in vivo dopamine release in the rat striatum and nucleus accumbens. Journal of Neuroscience, 24: 3235-3241.

Desmeules, J.A.; Piguet, V.; Collart, L. and Dayer, P. (1996). Contribution of monoaminergic modulation to the analgesic effect of tramadol. British Journal of Clinical Pharmacology, 41:7-12.

Ellman, G.L.; Courtney, K.L.; Andres, V.Jr. and Featherstone, R.M. (1961). A new and rapid colorimetric determination of acetylcholinesterase activity. Biochemistry and Pharmacology, 7: 88-95.

EIShebiney, S.A.; El-Denshary, E.S.; Abdel-Salam, O.M.; Salem, N.A.; El-Khyat, Z.A.; Shaffie, N.E.; et al. (2014). Cannabis resin extract in Parkinson's disease: Behavioral, Neurochemical, and Histological Evaluation. Cell Biology: Research \& Therapy, 3(1).

Frink, M.C.; Hennies, H.H.; Englberger, W.; Haurand, M. and Wilffert, B. (1996). Influence of tramadol on neurotransmitter systems 
of the rat brain.

Arzneimittelforschung, 46(11):10291036.

Gallagher, D.A.; Lees, A.J. and Schrag, A. (2010). What are the most important nonmotor symptoms in patients with Parkinson's disease and are we missing them?. Movement Disorders, 25: 2493-2500. doi:10.1002/mds.23394

Gan, K.; Smolen, A.; Eckerson, H. and La Du, B. (1991). Purification of human serum paraoxonaselarylesterase: evidence for one esterase catalyzing both activities. Drug Metabolism and Disposition, 19: 100-106.

Gan, S.H.; Ismail, R.; Wan Adnan, W.A. and Zulmi, W. (2007). Impact of CYP2D6 genetic polymorphism on tramadol pharmacokinetics and pharmacodynamics. Molecular Diagnosis and Therapy, 11: 171-181.

\section{Ghoneim, F.M.; Khalaf, H.A.;} Elsamanoudy, A.Z. and Helaly, A.N. (2014). Effect of chronic usage of tramadol on motor cerebral cortex and testicular tissues of adult male albino rats and the effect of its withdrawal: histological, immunohistochemical and biochemical study. International journal of clinical and experimental pathology, 7(11):7323-7341.

Gillen, C.; Haurand, M.; Kobelt, D.J. and Wnendt, S. (2000). Affinity, potency and efficacy of tramadol and its metabolites at the cloned human mu-opioid receptor. Naunyn-
Schmiedeberg's Archives of Pharmacology, 362:116-121.

Grond, S. and Sablotzki, A. (2004). Clinical pharmacology of tramadol. Clinical pharmacokinetics, 43(13): 879-923.

Han, S.H.; Kim, Y.H. and Mook-Jung, I. (2011). RAGE: the beneficial and deleterious effects by diverse mechanisms of actions. Moleculeas and Cells, 31 (2): 91-97.

Hassanian-Moghaddam, H.; Farajidana, H.; Sarjami ,S. and Owliaey, H. (2013). Tramadolinduced apnea. The American Journal of Emergency Medicine, 31(1): 2631.

Hasselmo, M.E. and Sarter, M. (2011). Modes and models of forebrain cholinergic neuromodulation of cognition.

Neuropsychopharmacology, 36: 5273

Jenner, P. (2003). Oxidative stress in Parkinson's disease. Annals of Neurology, 53(S3).

Kish ,S.J.; Tong, J.; Hornykiewicz, O.; Rajput, A.; Chang, L.J.; Guttman, M. and Furukawa, Y. (2008). Preferential loss of serotonin markers in caudate versus putamen in Parkinson's disease. Brain, 131(Pt 1):120-31.

Klegeris, A.; Korkina, L.G. and Greenfield, S.A. (1995). A possible interaction between acetylcholinesterase and dopamine molecules during autoxidation of the 
amine. Free Radical Biology and Medicine, 18: 223-230.

Lang, A.E. (1984). Treatment of Parkinson's disease with agents other than levodopa and dopamine agonists: controversies and new approaches. Canadian Journal of Neurological Sciences, 11(1 suppl):210-220.

Lima-Cabello, E.; Garcia-Guirado, F.; Calvo-Medina, R.; El Bekay, R.; Perez-Costillas, L.; QuinteroNavarro, C.; et al. (2016). An Abnormal Nitric Oxide Metabolism Contributes to Brain Oxidative Stress in the Mouse Model for the Fragile X Syndrome, a Possible Role in Intellectual Disability. Oxidative medicine and cellular longevity, 2016, 8548910. doi:10.1155/2016/8548910

Liu, Y.M.; Zhu, S.M.; Wang, K.R.; Feng, Z.Y. and Chen, Q.L. (2008). Effect of tramadol on immune responses and nociceptive thresholds in a rat model of incisional pain. Journal of Zhejiang University Science B; 9:895-902.

Manjunath, M.J. and Muralidhara, M. (2013). Effect of Withania somnifera supplementation on rotenone-induced oxidative damage in cerebellum and striatum of the male mice brain. Central Nervous System Agents in Medicinal Chemistry, 13(1):43-56.

Mansvelder, H.D.; Mertz, M. and Role, L.W. (2009). Nicotinic modulation of synaptic transmission and plasticity in cortico-limbic circuits. Seminars in
Cell and Developmental Biology, 20: 432-440.

Mellor, K., Ahmed, A. and Thomson, A. (2009). Tramadol hydrochloride use and acute deterioration in Parkinson's disease tremor. Movement Disorders, 24: 622-623.

Miguez, J. M.; Aldegunde, M.; PazValinas, L.; Recio, J. and SanchezBarcelo, E. (1999). Selective changes in the contents of noradrenaline, dopamine and serotonin in rat brain areas during aging. Journal of Neural Transmission, 106(11-12), 10891098.

Moshage, H.; Kok, B.; Huizenga, J.R. and Jansen, P.L. (1995). Nitrite and nitrate determinations in plasma: a critical evaluation. Clinical Chemistry, 41: 892-896.

Nagakannan, P.; Dhadde, S.B.; Shivanandappa, T.B. and Veerapur, V. (2012). Effect of tramadol on behavioral alterations and lipid peroxidation after transient forebrain ischemia in rats. Toxicology mechanisms and methods, 22 (9): 674-678.

Obeso, J.A.; Rodriguez-Oroz, M.C.; Goetz, C.G.; Marin, C.; Kordower, J.H.; Rodriguez, M.; Hirsch, E.C.; Farrer, M.; Schapira, A.H. and Halliday, G. (2010). Missing pieces in the Parkinson's disease puzzle. Nature Medicine, 16 (6): 653-661.

Raffa, R.B.; Friderichs, E.; Reimann, W.; Shank, R.P.; Codd, E.E. and Vaught, J.L. (1992). Opioid and nonopioid components independently 
contribute to the mechanism of action of tramadol, an'atypical'opioid analgesic. Journal of Pharmacology and Experimental Therapeutics, 260(1): 275-285.

Raffa, R.B. (2008). Basic pharmacology relevant to drug abuse assessment: tramadol as example. Journal of Clinical Pharmacy and Therapeutics, 33: 101-108.

Rosenblat, M.; Gaidukov, L.; Khersonsky, O.; Vaya, J.; Oren, R., Tawfik, D.S. and Aviram, M. (2006). The catalytic histidine dyad of high density lipoprotein-associated serum paraoxonase-1 (PON1) is essential for PON1-mediated inhibition of low density lipoprotein oxidation and stimulation of macrophage cholesterol efflux. J. Biol. Chem. 281, 7657-7665.

Sacerdote, P.; Bianchi, M.; Manfredi, B. and Panerai, A.E. (1997). Effects of tramadol on immune responses and nociceptive thresholds in mice. Pain, 72: 325-330.

Saravanan, K.S.; Sindhu, K.M.; Senthilkumar, K.S. and Mohanakumar, K.P. (2006). Ldeprenyl protects against rotenoneinduced, oxidative stress-mediated dopaminergic neurodegen-eration in rats. Neurochemistry International, 49:28-40.

Schapira, A.H. and Jenner, P. (2011). Etiology and pathogenesis of Parkinson's disease. Movement Disorders, 26:1049-1055.
Scholtissen, B.; Verhey, F.R.J.; Steinbusch, H.W.M. and Leentjens, A.F.G. (2006). Serotonergic mechanisms in Parkinson's disease: opposing results from preclinical and clinical data. Journal of Neural Transmission, 113: 59-73.

Schwab, R.S. and Leigh, D. (1939). Parpanit in the treatment of Parkinson's disease. JAMA, 139:629-634.

Sen, S.; Doger, F.K.; Ogurlu, M.; Aydın, O.N.; Akcal, Z.; Sen, S. and Karul, A. (2013). The Efficacy of Tramadol Combined with A Donor of NO, Glyceryl Trinitrate (GTN) Mixture on Cytokines, NF-KB Expression and Oxidative Stress Marker in the Rat Model of Formalin-Induced Inflammation. British Journal of Medicine and Medical Research, 3(4): 1988-1998.

Sherer, T.B.; Kim, J.H.; Betarbet, R. and Greenamyre, J.T. (2003). Subcutaneous rotenone exposure causes highly selective dopaminergic degeneration and $\alpha$-synuclein aggregation. Experimental Neurology, 179(1): 9-16.

Sherer, T.B.; Richardson, J.R.; Testa, C.M.; Seo, B.B.; Panov, A.V.; Yagi T, et al. (2007). Mechanism of toxicity of pesticides acting at complex 1: relevance to environmental etiologies of Parkinson's disease. Journal of Neurochemistry, 100(6):1469-79.

Smith, Y. and Villalba, R. (2008). Striatal and extrastriatal dopamine in the basal ganglia: an overview of its 
anatomical organization in normal and Parkinsonian brains. Movement Disorders, 23(Suppl. 3): S534-S547.

Somogyi, A.A.; Barratt, D.T. and Coller, J.K. (2007). Pharmacogenetics of opioids. Clinical Pharmacology and Therapy, 81: 429444.

Stein, W.M. and Read S. (1997). Chronic pain in the setting of Parkinson's disease and depression. Journal of Pain and Symptom Management, 14(4): 255-258.

Steinert, J. R.; Chernova, T. and Forsythe, I. D. (2010). Nitric oxide signaling in brain function, dysfunction, and dementia. Neuroscientist, 16(4):435452.

Swathi, G.; Bhuvaneswar, C. and Rajendra, W. (2013). Alterations of cholinergic neurotransmission in rotenone induced Parkinson's disease: protective role of Bacopa Monnieri. IJPBS, 3( 2): 286-292.

Takeshita, J. and Litzinger, M.H. (2009). Serotonin syndrome associated with tramadol. Primary care companion to the Journal of Clinical Psychiatry, 11(5):273.

Takhtfooladi, M.A.; Jahanshahi, A.; Sotoudeh, A.; Daneshi, M.H.; Aslani, K. and Takhtfooladi, H.A. (2014). Neuroprotective effects of tramadol on cerebral injuries caused by hind limb ischaemia/reperfusion in rats. Comparative Clinical Pathology, 23(5): 1141-1146.
Tashakori, A. and Afshari, R. (2010). Tramadol overdose as a cause of serotonin syndrome: A case review. Clinical Toxicology; 48:337-341.

Taylor, J.M.; Main, B.S. and Crack, P.J. (2013). Neuroinflammation and oxidative stress: co-conspirators in the pathology of Parkinson's disease. Neurochemistry International, 62(5):803-819.

Tsai, Y.C.; Sung, Y.H.; Chang, P.J.; Kang, F.C. and Chu, K.S. (2000). Tramadol relieves thermal hyperalgesia in rats with chronic constriction injury of the sciatic nerve. Fundamental and clinical pharmacology, 14(4), 335-340.

Tufi, R.; Gandhi, S.; De Castro, I.P.; Lehmann, S.; Angelova, P.R.; Dinsdale, D.; et al. (2014). Enhancing nucleotide metabolism protects against mitochondrial dysfunction and neurodegeneration in a PINK1 model of Parkinson's disease. Nature Cell Biology, 16(2):157.

Uchiyama, M. and Mihara, M. (1978). Determination of malonaldehyde precursor in tissues by thiobarbituric acid test. Analytical Biochemistry, 86:271-278.

Volpe, D.A.; Tobin, G.A.; Mellon, R.D.; Katki, A.G.; Parker, R.J.; Colatsky, T.; et al. (2011). Uniform assessment and ranking of $\mathrm{Mu}$ receptor binding constants for selected opioid drugs. Regulatory Toxicology and Pharmacology, 59:385-390. 
Wallace, V.C. and Chaudhuri, K.R. (2014). Unexplained lower limb pain in Parkinson's disease: A phenotypic variant of "painful Parkinson's disease". Parkinsonism \& related disorders, 20(1): 122-124.

Zaitone, S.A.; Abo-Elmatty, D.M. and Shaalan, A.A. (2012). Acetyl-L- carnitine and $\alpha$-lipoic acid affect rotenone-induced damage in nigral dopaminergic neurons of rat brain, implication for Parkinson's disease therapy. Pharmacology, Biochemistry and Behavior, 100(3):347-360. 
التغيرات النيوروكيميائية والهستولوجية في المخ الناجمة عن اعطاء دواء الترامادول للجرذان المصابة بمرض بوض الشلل الرعاش بواسطة الروتنون اعطون

\author{
شيماء الثبيني 1، داليا أبو الفضل²، عمر محمد عبدالسلام1 \\ 1 قسم بحوث المخدر ات و المنشطات و السموم، المركز القومي للبحوث، القاهرة، مصر \\ 2²م بحوث الباثولوجيا، المركز القومي للبحوث، القاهرة، مصر
}

المر اسلة: د.شيماء الثبيني، المركز القومي للبحوث، 33 ش البحوث الدقي، مصر. shaimaaelshebiney@gmail.com

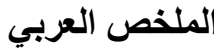

الههف: يعاني أكثر من 30\% من مرضى الثلل الرعاث من آلام جسديةمزمنة تقلل من جودة حياتهم. ومن أكثر

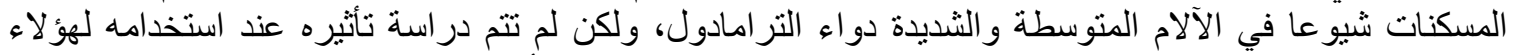

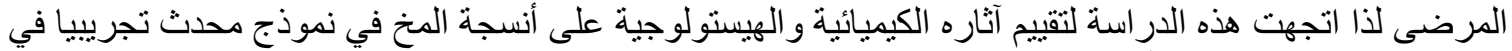

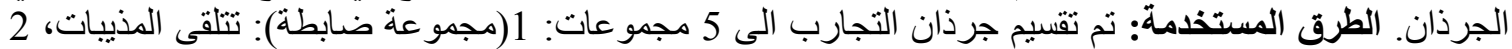

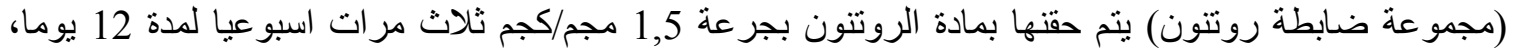

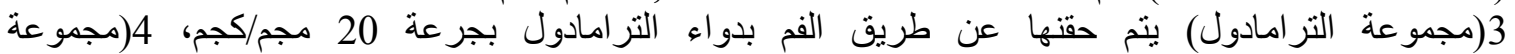

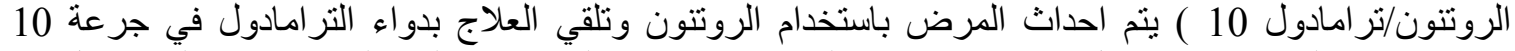

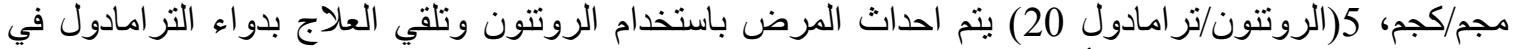

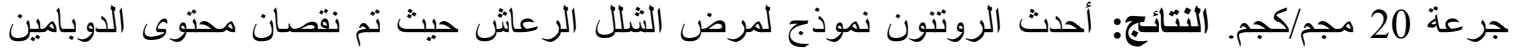

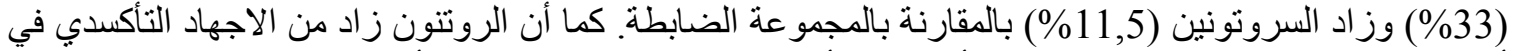

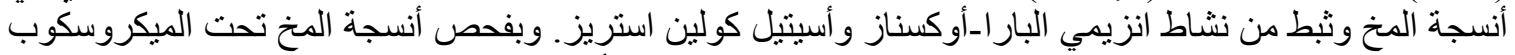

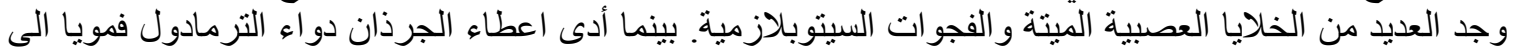

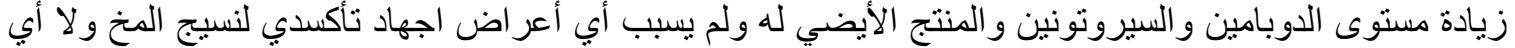

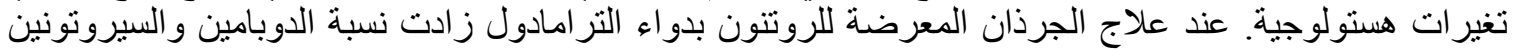

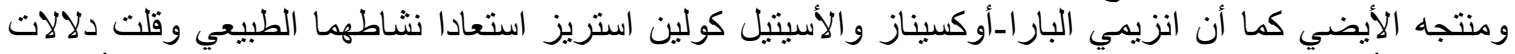

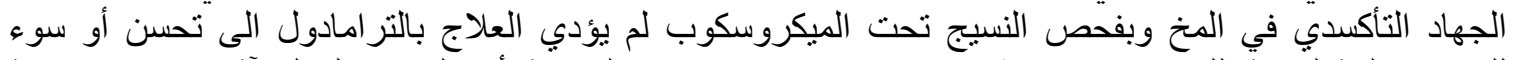

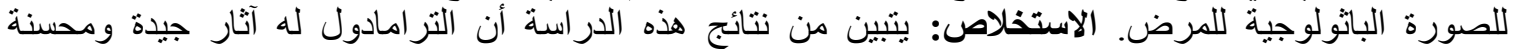

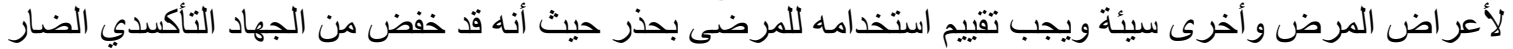

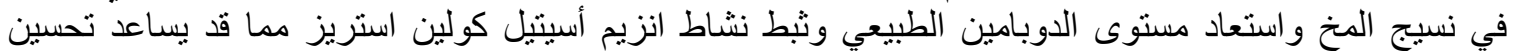

أعر اض المرض. ولكنه سبب اثار ا سيئة مثل زيادة مستوى معامل الالتهاب و وأز اد مستوى السيروتونين النين.

$$
\text { الكلمات الدالة: الثلل الر عاش: الاجهاد التأكسدي ، معامل موت الأورام ألفا، الروتنون، تر امادول }
$$

